\title{
PKMS Kampung Lele, Desa Pantai Raja, Kecamatan Perhentian Raja, Kabupaten Kampar
}

\author{
Nofripa Herlina*, Novia Gesriantuti, Shabri Putra Wirman, Elsie Elsie, Israwati \\ Harahap, Yeeri Badrun, Yulia Fitri
}

Fakultas MIPA dan Kesehatan, Universitas Muhammadiyah Riau

email: : nofripaherlina@umri.ac.id

\begin{abstract}
Partners in the Stimulus Community Partnership Program (PKMS) are RT 08 RW 02 Pantai Raja Village, Perhentian Raja District, Kampar Regency. This partner group has a business as a catfish breeder (Clarias sp.). Catfish hatchery efforts in Pantai Raja Village have started 8 years ago. The government also played an active role in developing the catfish farming business in the village. Catfish cultivation business is carried out using tarpaulin ponds. The number of ponds owned by each partner is around 25-30 pools / person. Catfish cultivation in this village includes hatchery and enlargement business activities. However, there are problems faced by catfish farmers, namely catfish attacked by diseases and death such as fungal diseases, white spots on the body of the fish. This is thought to be caused by water quality that is not good (poisonous) as well as a lot of residual fish residue at the bottom of the pond. Based on this, the team from the Stimulus Community Partnership Program (PKMS) Muhammadiyah University of Riau (UMRI) has conducted mentoring and monitoring activities to help resolve problems from partners. The forms of activities that have been carried out are socialization and training in aquaponics making. Based on discussions with participants during the socialization and training, it can be seen that participants' knowledge of good aquaponics is felt to be very lacking. With this dedication activity, the participants already have knowledge about aquaponics cultivation, so that participants will be able to carry out independently.
\end{abstract}

Keywords: Aquaponics, cultivation, Pantai Raja Village, Catfish (Clarias sp.)

\begin{abstract}
Abstrak
Mitra dalam Program Kemitraan Masyarakat Stimulus (PKMS) adalah RT 08 RW 02 Desa Raja, Kecamatan Perhentian Raja, Kabupaten Kampar. Kelompok mitra ini memiliki bisnis sebagai pemulia ikan lele (Clarias sp.). Upaya pembenihan ikan lele di Desa Pantai Raja telah dimulai 8 tahun yang lalu. Pemerintah juga memainkan peran aktif dalam mengembangkan bisnis budidaya ikan lele di desa. Usaha budidaya ikan lele dilakukan dengan menggunakan kolam terpal. Jumlah kolam yang dimiliki oleh masing-masing pasangan adalah sekitar 25-30 kolam / orang. Budidaya ikan lele di desa ini meliputi kegiatan pembenihan dan pembesaran. Namun, ada masalah yang dihadapi oleh petani ikan lele, yaitu ikan lele yang terserang penyakit dan kematian seperti penyakit jamur, bercak putih di tubuh ikan. Hal ini diduga disebabkan oleh kualitas air yang tidak baik (beracun) serta residu ikan yang banyak di dasar kolam. Berdasarkan hal ini, tim dari Program Kemitraan Masyarakat Stimulus (PKMS) Universitas Muhammadiyah Riau (UMRI) telah melakukan kegiatan pendampingan dan pemantauan untuk membantu menyelesaikan masalah dari mitra. Bentuk kegiatan yang telah dilakukan adalah sosialisasi dan pelatihan pembuatan aquaponik. Berdasarkan diskusi dengan peserta selama sosialisasi dan pelatihan, dapat dilihat bahwa pengetahuan peserta tentang aquaponik yang baik dirasakan sangat kurang. Dengan kegiatan pengabdian ini, para peserta sudah memiliki pengetahuan tentang budidaya aquaponik, sehingga para peserta akan dapat melakukan secara mandiri.
\end{abstract}

Kata Kunci: Aquaponik, budidaya, Desa Pantai Raja, Lele (Clarias sp.) 


\section{PENDAHULUAN}

Usaha budidaya lele di Desa Pantai Raja, Kecamatan Perhentian Raja, Kabupaten Kampar memiliki potensi yang cukup besar untuk dikembangkan. Usaha pembenihan lele di desa tersebut sudah dimulai sejak 8 tahun yang lalu. Pada awalnya, usaha budidaya lele hanya dilakukan oleh beberapa orang saja, namun karena usaha ini memiliki peluang usaha yang cukup besar dan proses produksinya tidak terlalu sulit, maka usaha budidaya lele ini mulai diikuti masyarakat lainnya yang ada di Desa Pantai Raja tersebut. Pemerintah sangat berperan dalam pengembangan usaha budidaya lele. Keterlibatan pemerintah tersebut yakni peningkatan ilmu pengetahuan mengenai budidaya lele melalui penyuluhan, hal ini menyebabkan peningkatan yang pesat terhadap usaha budidaya lele di Desa Pantai Raja, sehingga dikenal dengan sebutan Kampung Lele.

Pembudidaya memilih melakukan budidaya lele karena teknologi budidaya relatif mudah diterapkan, sehingga dapat dibudidayakan pada lahan yang terbatas. Proses produksi yang relatif cepat dengan hasil produksi dalam sekali panen hingga 3 ton. Permintaan pasar yang semakin tinggi dan minat konsumsi terhadap ikan lele juga terus meningkat, sehingga membuat pembudidaya lele di Desa Pantai Raja terus terpacu untuk mengembangkan usahanya.

Usaha budidaya lele yang telah dikembangkan yaitu dengan menggunakan kolam terpal. Jumlah kolam yang dimiliki oleh masing-masing mitra sekitar 20-25 kolam/orang. Budidaya lele di Desa Pantai Raja meliputi kegiatan usaha pembenihan dan pembesaran. Berdasarkan hasil wawancara dengan salah satu masyarakat di desa tersebut, terdapat permasalahan yang sering dihadapi oleh pembudidaya lele yaitu ikan lele terserang penyakit dan kematian. Hal ini diduga disebabkan oleh kualitas air yang kurang baik (beracun) serta banyak endapan sisa kotoran ikan di dasar kolam. Permasalahan ini harus segera ditanggulangi agar usaha budidaya lele tetap menjadi andalan Kampung Lele.

Berdasarkan hal tersebut, tim dari Program Kemitraan Masyarakat Stimulus (PKMS) Universitas Muhammadiyah Riau (UMRI) akan melakukan kegiatan pendampingan dan monitoring untuk membantu menyelesaikan permasalahan mitra. Bentuk kegiatan yang akan dilakukan yaitu dengan memperkenalkan akuaponik. Akuaponik adalah kombinasi antara akuakultur dengan hidroponik yang menghasilkan simbiosis mutualisme atau saling menguntungkan. Akuakultur merupakan budidaya ikan, sedangkan hidroponik adalah budidaya tanaman tanpa tanah yang berarti budidaya tanaman yang memanfaatkan air dan tanpa menggunakan tanah sebagai media tanam atau soilles. Akuaponik memanfaatkan secara terus menerus air dari pemeliharaan ikan ke tanaman ke kolam ikan (Rakocy, et al., 2006). Sistem akuaponik dalam prosesnya menggunakan air dari kolam ikan, kemudian disirkulasikan kembali melalui suatu pipa tempat tanaman akan ditumbuhkan. Kemudian tanaman ini akan berfungsi sebagai filter vegetasi, yang akan mengurai zat racun tersebut menjadi zat yang tidak berbahaya bagi ikan. Jadi, inilah siklus yang saling menguntungkan agar ikan yang ada di kolam dapat terhindar dari penyakit dan kematian.

Budidaya ikan yang dikombinasikan dengan sayuran akan lebih menarik, dan diharapkan dapat dilakukan secara berkelanjutan. Apabila kegiatan ini berlanjut, maka selain sebagai sentra lele Kampung Lele juga akan memiliki peluang sebagai pemasok sayur organik untuk Kota Pekanbaru. Teknologi budidaya lele secara akuaponik diharapkan tidak menyebabkan turunnya produksi ikan lele karena kematian dan dapat memproduksi sayuran yang sehat/organik tanpa pupuk kimia.

Mitra dalam Program Kemitraan Masyarakat ini adalah RT 08 RW 02 Desa Pantai Raja, Kecamatan Perhentian Raja, Kabupaten Kampar. Mitra akan 
memberikan 3 orang masyarakat yang akan mengikuti pelatihan sebagai kader. Pembentukan kader ini akan memudahkan dalam transfer informasi materi ke masyarakat setempat. Berdasarkan uraian di atas, maka program kegiatan ini dilakukan untuk membantu masyarakat Kampung Lele dalam penerapan teknologi akuaponik yaitu integrasi antara budidaya lele dengan tanaman sawi sebagai usaha ekonomi mikro masyarakat Kampung Lele, Desa Pantai Raja, Kecamatan Perhentian Raja, Kabupaten Kampar.

\section{SOLUSI PERMASALAHAN}

Telah dijelaskan sebelumnya bahwa mitra yang menjadi sasaran Program Kemitraan Masyarakat Stimulus (PKMS) adalah RT 08 RW 02 Desa Pantai Raja, Kecamatan Perhentian Raja, Kabupaten Kampar. Secara khusus permasalahan yang dihadapi oleh mitra tersebut adalah kualitas air kolam lele yang kurang baik (beracun) serta banyak endapan sisa kotoranikandi dasar kolam, sehingga menyebabkan kematian pada ikan. Teknologi akuaponik dapat menjadi salah satu solusi dari permasalahan tersebut. Nugroho et al. (2012) menyatakan bahwa teknologi akuaponik merupakan gabungan teknologi akuakultur dengan teknologi hidroponik dalam satu sistem untuk mengoptimalkan fungsi air dan ruang sebagai media pemeliharaan. Teknologi tersebut telah dilakukan di negara-negara maju, khususnya yang memiliki keterbatasan lahan untuk mengoptimalkan produktifitas biota perairan. Prinsip dasar yang bermanfaat bagi budidaya perairan adalah sisa pakan dan kotoran ikan yang berpotensi memperburuk kualitas air, akan dimanfaatkan sebagai pupuk bagi tanaman air. Pemanfaatan tersebut melalui sistem resirkulasi air kolam yang disalurkan ke media tanaman, yang secara mutualistis juga menyaring air tersebut sehingga saat kembali ke kolam menjadi "bersih" dari anasir ammonia dan mempunyai kondisi yang lebih layak untuk budidaya ikan. Dengan adanya Program Kemitraan
Masyarakat Stimulus (PKMS) ini diharapkan permasalahan yang dihadapi oleh pembudidaya lele dapat teratasi.

Berdasarkan permasalahan yang dihadapi oleh mitra tersebut, maka Universitas Muhamadiyah Riau (UMRI), sebagai satu-satunya perguruan tinggi swasta di Pekanbaru yang memiliki Fakultas MIPA merasa memiliki kesempatan dan tanggung jawab untuk membantu permasalahan yang dihadapi oleh mitra.

Fakultas MIPA, UMRI memiliki SDM (Dosen) yang memiliki kepakaran pada bidang tumbuhan, hewan dan Fisika yang dapat mentransfer keilmuannya dan keterampilan kepada pembudidaya lele. Pada kegiatan ini juga akan dibantu oleh 2 orang mahasiswa yang sebelumnya telah berhasil dalam budidaya sayuran dengan system hidroponik. Setelah dilakukan pendampingan diharapkan pembudidaya lele ini berperan sebagai pioner bagi masyarakat disekitarnya untuk menularkan ilmu danketerampilan yang sudah mereka miliki. Transfer ilmu akan dilakukan dalam bentuk sosialisasi dan memberikan keterampilan, pendampingan dan pengawasan. Selain SDM dengankepakarannya diperlukan juga saranadanprasarana yang mendukung dan sesuai dengan kebutuhan kegiatan PKMS yang akan dilaksanakan dengan mitra.

Solusi permasalahan dan target luaran yang ingin dicapai dalam kegiatan ini, diuraikan dalam bentuk Tabel 1 berikut:

Tabel 1. Solusi penyelesaian permasalahan yang ditawarkan dari pelaksanaan PKMS

\begin{tabular}{|c|c|c|}
\hline Permasalahan & Penyebab & Solusi yang ditawarkan \\
\hline $\begin{array}{l}\text { Rendahnya kualitas air } \\
\text { kolam lele, sehingga } \\
\text { menimbulkan penyakit } \\
\text { dan kematian pada lele } \\
\text { yang dibudidayakan. }\end{array}$ & $\begin{array}{l}\text { Menumpuknya } \\
\text { limbah-limbah } \\
\text { atau sisa-sisa } \\
\text { kotoran ikan di } \\
\text { dasar kolam } \\
\text { yang bersifat } \\
\text { racun bagi ikan. }\end{array}$ & $\begin{array}{l}\text { - Sosialisasi tentang upaya } \\
\text { mencegah kematian ikan lele } \\
\text { dalam kolam pembesaran } \\
\text { - Memberikan keterampilan } \\
\text { pembuatan sistem akuaponik } \\
\text { - Pendampingan dan monitoring } \\
\text { terhadap sistem akuaponik } \\
\text { percontohan }\end{array}$ \\
\hline
\end{tabular}


ISSN : 2550-0198

Tabel 2. Solusi, luaran beserta spesifikasinya yang hendak dicapai pada Program Kemitraan Masyarakat Stimulus (PKMS)

\begin{tabular}{|l|l|l|}
\hline \multicolumn{1}{|c|}{ Solusi } & \multicolumn{1}{|c|}{ Luaran } & \multicolumn{1}{c|}{ Spesifikasi } \\
\hline - Sosialisasi tentang upaya \\
mencegah kematian ikan \\
lele dalam kolam \\
$\begin{array}{l}\text { pembesaran. } \\
\text { Memberikan menerapkan } \\
\text { keterampilan pembuatan } \\
\text { sistem akuaponik } \\
\text { (Sistem akuaponik } \\
\text { model aliran atas). }\end{array}$ & $\begin{array}{l}\text { Air kolam menjadi } \\
\text { lebih higienis. } \\
\text { Petani lele dapat } \\
\text { tambahan akuaponik } \\
\text { penghasilan berupa } \\
\text { sayuran hidroponik. }\end{array}$ \\
$\begin{array}{l}\text { Pendampingan dan } \\
\text { monitoring terhadap } \\
\text { sistem akuaponik } \\
\text { percontohan }\end{array}$ & \\
\hline
\end{tabular}

\section{METODE PENGABDIAN}

\section{Tahapan Pelaksanaan Program}

Program Kemitraan Masyarakat Stimulus (PKMS) akan dilaksanakan selama 6 bulan di RT 08 RW 02,Desa Pantai Raja, Kecamatan Perhentian Raja, Kabupaten Kampar dengan 4 (empat) tahapan kegiatan pokok. Rincian kegiatan disajikan pada Tabel 3 berikut.

Tabel 3. Tahapan Kegiatan Program Kemitraan Masyarakat

\begin{tabular}{|c|l|}
\hline Tahapan & \multicolumn{1}{|c|}{ Kegiatan } \\
\hline I & Persiapan Program peralatan \\
\hline & $\begin{array}{l}\text { Pengadaan pelatihan dan } \\
\text { pebutuhan pendampingan }\end{array}$ \\
\hline II & Sosialisasi Program \\
\hline III & Implementasi Program \\
\hline & $\begin{array}{l}\text { Pelatihan dan } \\
\text { pendampingan pembuatan } \\
\text { kolam percontohan dengan } \\
\text { sistem akuaponik }\end{array}$ \\
\hline IV & Evaluasi dan Monitoring \\
\hline & Pengawasan pelaksanaan \\
\hline
\end{tabular}

\section{Jenis Kepakaran yang dibutuhkan untuk menyelesaikan persoalan}

Adapun sumberdaya manusia yang terlibat dalam kegiatan ini adalah dosen yang memiliki kepakaran untuk menyelesaikan persoalan mitra dan mahasiswa yang membantu aspek teknis. Berikut disajikan dalam Tabel 4.

Tabel 4. Kepakaran yang dibutuhkan untuk menyelesaikan persoalan

\begin{tabular}{|c|c|c|c|}
\hline $\begin{array}{c}\text { Tim } \\
\text { Pengusul }\end{array}$ & Peran & Kepakaran & $\begin{array}{c}\text { Deskripsi } \\
\text { Tugas }\end{array}$ \\
\hline $\begin{array}{l}\text { Nofripa } \\
\text { Herlina }\end{array}$ & Ketua & Botani & $\begin{array}{l}\text { 1. Mengorganisa } \\
\text { sikan program } \\
\text { 2. Berkoordinasi } \\
\text { dengan mitra } \\
\text { dan pihak- } \\
\text { pihak terkait } \\
\text { 3. Mempersiapk } \\
\text { an bahan dan } \\
\text { peralatan } \\
\text { yang } \\
\text { dibutuhkan } \\
\text { selama } \\
\text { kegiatan. } \\
\text { 4. Berperan } \\
\text { membantu } \\
\text { proses } \\
\text { pelatihan. } \\
\text { 5. Perencanaan } \\
\text { dan pelaporan } \\
\text { kegiatan. }\end{array}$ \\
\hline $\begin{array}{l}\text { Novia } \\
\text { Gesriantu } \\
\text { ti }\end{array}$ & $\begin{array}{l}\text { Anggot } \\
\mathrm{a}\end{array}$ & Zoologi & $\begin{array}{l}\text { 1.Perancangan } \\
\text { metode } \\
\text { penyuluhan } \\
\text { dan sosialisasi } \\
\text { program. } \\
\text { 2. Mendesain } \\
\text { pelaksanaan } \\
\text { program } \\
\text { pelatihan. } \\
\text { 3. Mendesain } \\
\text { model } \\
\text { pengawasan } \\
\text { dan evaluasi } \\
\text { program. } \\
\text { 4. Menyusun } \\
\text { laporan hasil } \\
\text { evaluasi } \\
\text { Program. } \\
\text { 5. Berperan } \\
\text { membantu } \\
\text { proses } \\
\text { pelatihan }\end{array}$ \\
\hline $\begin{array}{l}\text { Shabri } \\
\text { Putra } \\
\text { Wirman }\end{array}$ & $\begin{array}{l}\text { Anggot } \\
\mathrm{a}\end{array}$ & $\begin{array}{l}\text { Fisika } \\
\text { (Elektronika } \\
\text { dan } \\
\text { Instrumentas } \\
\text { i) }\end{array}$ & $\begin{array}{l}\text { 1. Perancangan } \\
\text { metode } \\
\text { penyuluhan } \\
\text { dan sosialisasi } \\
\text { program. } \\
\text { 2. Mendesain } \\
\text { pelaksanaan } \\
\text { program } \\
\text { pelatihan. } \\
\text { 3. Mendesain } \\
\text { model } \\
\text { pengawasan } \\
\text { dan evaluasi } \\
\text { program. }\end{array}$ \\
\hline
\end{tabular}




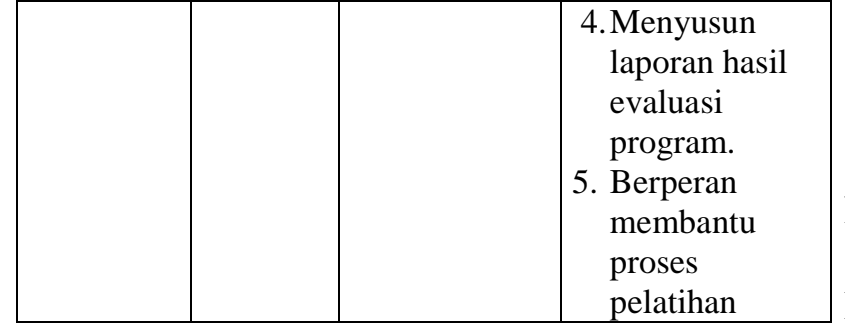

\section{Evaluasi Program}

Pada tahap ini, dilakukan evaluasi terhadap program yang telah dilaksanakan selama 6 bulan (24 minggu). Tahap Evaluasi dilakukan untuk mengetahui keberhasilan dari program yang telah dilaksanakan. Secara garis besar tahapan tersebut meliputi: identifikasi kegiatan program, bentuk pelaksanaan evaluasi dan dihasilkan rancangan/ model sistem akuaponik yang direncanakan. Bentuk kegiatan, evaluasi dan dokumen evaluasi disajikan pada Tabel 5 berikut:

Tabel 5. Kegiatan, evaluasi dan dokumen evaluasi

\begin{tabular}{|c|c|c|c|}
\hline $\begin{array}{l}\mathbf{N} \\
\mathbf{o}\end{array}$ & Kegiatan & $\begin{array}{c}\text { Bentuk } \\
\text { Evaluasi }\end{array}$ & $\begin{array}{c}\text { Dokumen } \\
\text { Evaluasi }\end{array}$ \\
\hline 1 & $\begin{array}{l}\text { Sosialisasi } \\
\text { program } \\
\text { kegiatan }\end{array}$ & $\begin{array}{l}\text { Pengumpula } \\
\mathrm{n} \\
\text { dokumentasi } \\
\text { sosialisasi, } \\
\text { pengisian } \\
\text { angket, } \\
\text { respons dan } \\
\text { tingkat } \\
\text { pemahaman } \\
\text { peserta } \\
\text { terhadap } \\
\text { sosialisasi } \\
\text { program } \\
\text { kegiatan. }\end{array}$ & $\begin{array}{l}\text { Daftar hadir } \\
\text { peserta, } \\
\text { dokumentas } \\
\text { i sosialisasi } \\
\text { dan } \\
\text { lembaran } \\
\text { isian } \\
\text { angket. }\end{array}$ \\
\hline 2 & $\begin{array}{l}\text { Pelatihan } \\
\text { pembuata } \\
\text { n sistem } \\
\text { akuaponik }\end{array}$ & $\begin{array}{l}\text { Pengumpula } \\
\mathrm{n} \\
\text { dokumentasi } \\
\text { pelatihan, } \\
\text { pengisian } \\
\text { angket, } \\
\text { respons dan } \\
\text { tingkat } \\
\text { pemahaman } \\
\text { peserta } \\
\text { terhadap } \\
\text { pelatihan } \\
\text { pembuatan }\end{array}$ & $\begin{array}{l}\text { Berita acara } \\
\text { pelaksanaan } \\
\text { pelatihan, } \\
\text { dokumentas } \\
\text { i pelatihan } \\
\text { dan } \\
\text { lembaran } \\
\text { isian } \\
\text { angket. }\end{array}$ \\
\hline
\end{tabular}



Data dan informasi yang diperoleh dari hasil pelaksanaan evaluasi tersebut, selanjutnya dianalisis secara kuantitatif dan kualitatif untuk membuat atau menarik kesimpulan.

\section{LUARAN DAN TARGET CAPAIAN}

Luaran dan target capaian dari kegiatan pengabdian ini disajikan pada Tabel 8 berikut:

Tabel 8. Rencana Target Capaian

\section{Luaran}

\begin{tabular}{|c|c|c|}
\hline No & Jenis Luaran & $\begin{array}{c}\text { Indikator } \\
\text { Capaian }\end{array}$ \\
\hline \multicolumn{3}{|c|}{ Luaran Wajib } \\
\hline 1 & $\begin{array}{l}\text { Publikasi ilmiah } \\
\text { pada jurnal ber } \\
\text { ISSN/ Prosiding } \\
\text { jurnal Nasional }^{1)}\end{array}$ & Publish \\
\hline 2 & $\begin{array}{l}\text { Publikasi pada } \\
\text { media masa cetak/ } \\
\text { online/repocitory } \\
\text { PT }^{6)}\end{array}$ & Terbit \\
\hline 3 & $\begin{array}{l}\text { Peningkatan daya } \\
\text { saing (peningkatan } \\
\text { kualitas, kuantitas, } \\
\text { serta nilai tambah } \\
\text { barang, jasa, } \\
\text { diversifikasi } \\
\text { produk, } \\
\text { sumber atau } \\
\text { lainnya }{ }^{4)}\end{array}$ & Tidak ada \\
\hline 4 & $\begin{array}{l}\text { Peningkatan } \\
\text { penerapan iptek di } \\
\text { masyarakat } \\
\text { (mekanisasi, IT, } \\
\text { dan manajemen }{ }^{4)}\end{array}$ & Ada \\
\hline 5 & $\begin{array}{l}\text { Perbaikan tata nilai } \\
\text { masyarakat (seni } \\
\text { budaya, sosial, } \\
\text { politik, keamanan, } \\
\text { ketentraman, } \\
\text { pendidikan, } \\
\text { kesehatan }{ }^{2)}\end{array}$ & Ada \\
\hline \multicolumn{3}{|c|}{ Luaran Tambahan } \\
\hline
\end{tabular}




\begin{tabular}{|l|l|c|}
\hline 1 & $\begin{array}{l}\text { Publikasi di jurnal } \\
\text { internasional }^{11}\end{array}$ & Tidak ada \\
\hline 2 & $\begin{array}{l}\text { Jasa; rekayasa } \\
\text { sosial, metode atau } \\
\text { sistem, } \\
\text { produk/barang }\end{array}$ & Tidak ada \\
\hline 3 & Inovasi baru TTG ${ }^{5)}$ & Tidak ada \\
\hline 4 & $\begin{array}{l}\text { Hak kekayaan } \\
\text { intelektual (Paten, } \\
\text { Paten sederhana, } \\
\text { Hak Cipta, Merek } \\
\text { dagang, Rahasia } \\
\text { dagang, Desain } \\
\text { Produk Industri, } \\
\text { Perlindungan } \\
\text { Varietas Tanaman, } \\
\text { Perlindungan } \\
\text { Desain Topografi } \\
\text { Sirkuit Terpadu }\end{array}$ & \\
\hline 5 & Buku ber ISBN ${ }^{6)}$ & Tidak ada \\
\hline
\end{tabular}

Keterangan:

1) Isi dengan belum/ tidak ada, draf, submitted, reviewed, atau accepted/published

2) Isi dengan belum/ tidak ada, draf, terdaftar, atau sudah dilaksanakan

3) Isi dengan belum/ tidak ada, draf, atau terdaftar/ granted

4) Isi dengan belum/ tidak ada, produk, penerapan, besar peningkatan

5) Isi dengan belum/ tidak ada, draf, produk, atau penerapan

6) Isi dengan belum/ tidak ada, draf, proses editing/ sudah terbit

HASIL DAN PEMBAHASAN

Persiapan Kegiatan Pengabdian kepada Masyarakat

Penjajakan pertama dilakukan dengan menemui ketua RT 08 RW 02 Desa Pantai Raja, Kecamatan Perhentian Raja, Kabupaten Kampar. Selanjutnya dilakukan observasi langsung ke lapangan, yaitu melihat beberapa kolam lele milik salah satu warga di desa tersebut yang selanjutnya akan dijadikan sebagai kolam percontohan pada kegiatan pengabdian ini.

Kegiatan pengabdian dirancang untuk dapat dihadiri oleh anggota kelompok tani lele dengan mengundang sebanyak 20 orang peserta. Kegiatan pengabdian dimulai dari persiapan materi dalam bentuk power point, alat dan bahan penunjang.

\section{Pelaksanaan Kegiatan Sosialisasi}

Kegiatan pengabdian kepada masyarakat ini terbagi ke dalam 2 tahap, yaitu kegiatan sosialisasi dan kegiatan praktik pembuatan akuaponik yang diberikan kepada petani lele Desa Perhentian Raja, Kabupaten kampar. Dua kegiatan tersebut telah terselenggara sesuai dengan yang telah direncanakan. Kegiatan sosialisasi kepada kelompok tani lele telah dilaksanakan pada tanggal 29 Agustus 2019 bertempat di rumah salah satu warga Kampung Lele Desa Pantai Raja. Sebanyak 11 orang peserta hadir pada kegiatan sosialisasi tersebut. Kegiatan diawali dengan kata sambutan ketua pelaksana pengabdian Universitas Muhammadiyah Riau, selanjutnya pemaparan tentang teknologi akuaponik dan manfaatnya, diselingi dengan tanya jawab dengan peserta. Berikut adalah kegiatan penyampaian materi (Gambar 1).


Gambar 1. Penyampaian materi tentang teknologi akuaponik dan pemanfaatannya pada kolam lele

\section{Pelaksanaan Kegiatan Pelatihan pembuatan akuaponik pada kolam lele}

Pelatihan dilakukan pada hari Kamis, 12 September 2019. Kolam lele milik salah satu warga Kampung Lele Desa Pantai Raja, Kecamatan Perhentian Raja dijadikan sebagai kolam percontohan pembuatan sistem akuaponik yang telah disurvey sebelumnya. Pelatihan diikuti oleh beberapa orang peserta yang telah diundang sebagai mitra. Pada kegiatan pelatihan ini telah disiapkan sebelumnya bibit sayuran yang telah disemai selama 10 hari, rockwool, netpot dan $\mathrm{pH}$ meter. Pada saat kegiatan pelatihan dilakukan pemindahan 
bibit dengan cara meletakkan bibit sayuran yang telah tumbuh disemai ke dalam rockwool yang telah dibasahkan dengan air, yaitu dengan cara diberi lubang pada rockwool lalu dimasukkan bibitnya. Setelah itu diletakkan ke dalam netpot dan langsung dipindahkan ke dalam Aquaponik DFT (Deep Flow Technique) yang telah dibuat sebelumnya. Setelah semua bibit telah dipindakan selanjutnya diukur $\mathrm{pH}$ air pada kolam untuk mengetahui $\mathrm{pH}$ air kolam.

Kegiatan pelatihan ini juga diselingi dengan diskusi dan tanya jawab, dimana banyak pertanyaan peserta yang berhubungan dengan teknologi aquaponik. Selain itu terlihat minat peserta dalam berdiskusi dan bertanya mengenai budidaya aquaponik. Berdasarkan diskusi dengan peserta saat pelatihan, dapat diketahui bahwa pengetahuan peserta mengenai aquaponik yang baik dirasakan masih sangat kurang. Dengan adanya kegiatan pengabdian / pelatihan ini, maka peserta pengabdian telah memiliki pengetahuan tentang budidaya secara aquaponik, sehingga peserta akan dapat melaksanakannya secara mandiri. Terlihat bahwa peserta sangat antusias sekali dan ingin mengetahui dimana dan bagaimana cara untuk mendapatkan alat-alat dan bibit sayur-sayuran.

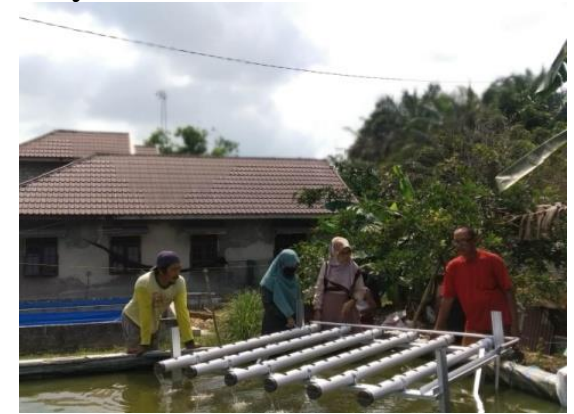

Gambar 2. Kegiatan Pelatihan pembuatan akuaponik bersama petani lele

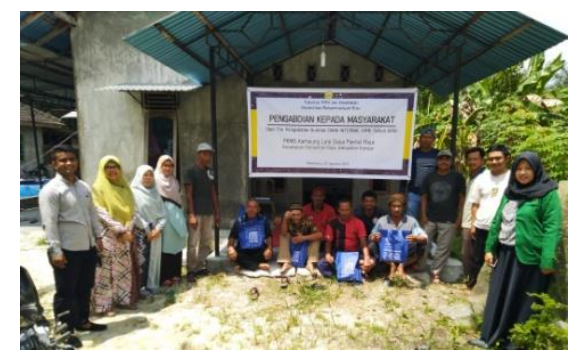

Gambar 3. Foto bersama peserta sosialisasi dan pelatihan pembuatan akuaponik

\section{SIMPULAN}

Berdasarkan dari kegiatan sosialisasi, seluruh materi yang disampaikan dapat diterima dengan baik oleh peserta. Hal ini dapat dibuktikan dari kegiatan diskusi dan tanya jawab, dimana banyak pertanyaan peserta yang berhubungan dengan teknologi akuaponik. Selain itu terlihat minat peserta dalam berdiskusi yang mana mereka ingin segera dapat mempraktikkan pembuatan akuaponik pada kolam lele di rumah mereka masing-masing. Berdasarkan diskusi dengan peserta saat sosialisasi, dapat diketahui bahwa pengetahuan petani lele mengenai akuaponik dirasakan masih kurang. Dengan adanya kegiatan pengabdian / sosialisasi ini, maka peserta pengabdian telah memiliki pengetahuan tentang penggunaan teknologi akuaponik pada kolam lele, sehingga peserta akan dapat melaksanakannya secara mandiri.

\section{DAFTAR PUSTAKA}

[1] Manurung RM, Kusai, Zulkarnain. The Change of analysis fish farmers mindset of Catfish cultivation in the Village Hangtuah of Perhentian Raja District of Kampar Regency Riau Province. Universitas Riau

[2] Nugroho RA, Pambudi LT, Chilmawati D, Haditomo AHC. 2012. Aplikasi Teknologi Akuaponik Pada Budidaya Ikan Air Tawar Untuk Optimalisasi Kapasitas Produksi. Jurnal Saintek Perikanan. Vol: 8 No: 1. Hal:46-51.

[3] Rakocy, J. E., M.P Masser dan T.M Losordo. 2006. Recirculating Aquaculture Tank Production Systems : Aquaponics - Integrating Fish and Plant Culture. Southern Regional Aquaculture Center, United States of Agriculture, USA. 